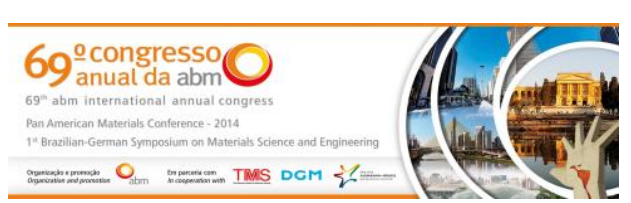

Theme: Physical Metallurgy and Materials Behavior at High Temperatures

\title{
EQUIVALENCE BETWEEN HOT TENSILE AND CREEP DATA IN ALUMINUM ALLOY AL7475-T7351. PART 2: ANALYSIS BY DIFFERENT PARAMETERIZATION METHODOLOGIES*
}

Gilmar Ferreira Bataglia ${ }^{1}$ Diego José Inforzato ${ }^{2}$ Erika Fernanda Prados ${ }^{3}$ Levi de Oliveira Bueno ${ }^{3}$

\begin{abstract}
The possibility of parameterization of hot tensile data together with creep data is investigated, for Aluminium Alloy 7475-T7351. This study represents part of a broader research program aiming at the validation of a methodology recently proposed for analyzing both kinds of data together, considering different metallic materials. The results presented in Part 1 of this work, were analyzed according to 4 traditional methods of the literature for parameterization of creep data, namely: Larson-Miller, Orr-Sherby-Dorn, Manson-Succop and Manson-Hafferd. The compatibility of the hot tensile test results with those of creep is remarkably good, indicating the possibility of using both kind of data together also in extrapolation schemes. The criterion proposed for equivalence between hot tensile and creep data is verified to work well also for this kind of material, under the present experimental conditions.
\end{abstract}

Keywords: hot tensile data, creep data, alloy AL7475-T7351, extrapolation procedures.

MSc/Material Engineering, Structures-Materials, Embraer, São José dos Campos, SP, Brazil.

PhD/Mechanical Engineering, Associate Professor, Mech. Engineering, USP, São Paulo, SP, Brazil.

3 DSc/Materials Engineering, Pos-Doc Researcher, Mech.Engineering, USP, São Paulo, SP, Brazil.

4 PhD/Materials Engineering, Associate Professor, Matls.Engineering, UFSCar, São Carlos, SP, Brazil.

* Technical contribution to the $69^{\text {th }}$ ABM International Annual Congress and to the ENEMET, July $21^{\text {st }}-25^{\text {th }}$, 2014, São Paulo, SP, Brazil. 


\section{INTRODUCTION}

This article represents a continuation of the work of analysis described in its Part 1 , which is also being presented in this conference [1].

The possibility of carrying out the parameterization of hot tensile data and creep data in AL7475-T7351 together, according to the traditional techniques of analysis commonly mentioned in literature, is now explored.

The procedure for converting the hot tensile data to creep-like data, according to the equivalence criterion proposed by Bueno [2], was described in detail in Part 1 of this work [1].

\subsection{Objective}

The objective is to verify the possibility of establishing a correlation among the results from these two kinds of test for AL7475-T7351, with a view to extrapolation of the data by different methodologies. This correlation was verified with success for different metallic materials, such as $2.25 \mathrm{Cr}-1 \mathrm{Mo}$ steeel [3], commercially pure copper [4], commercially pure aluminium [5] and brass [6].

Among the several possibilities related in literature, only 4 methods were selected, that can be considered as the most important in general for this kind of analysis, namely the methodologies of: Larson-Miller, Orr-Sherby-Dorn, Manson-Succop and Manson-Haferd.

\subsection{Methods of Parameterization}

There are a series of parameterization procedures that use equations relating temperature and rupture time for analysis of creep data. The definition of the various parameters are based in two aspects: the linearity and the pattern of arrangement that the points in iso-stress condition present in graphs of type LOG(Rupture Time) $x$ Temperature or LOG(Rupture Time) $x$ Inverse of Temperature. The different methods arise by the hypothesis of parallelism or convergence of these iso-stress lines in these diagrams.

According to Viswanathan[7], the four most important methods for parameterization of creep data are presented schematically in Figure 1.

Each of these methods presents a characteristic expression for its parameter, namely:
a) Larson-Miller method:
b) Orr-Sherby-Dorn method:
$P L M=T\left(C+L O G t_{r}\right)$
$P O S D=L O G t_{r}-A / T$
c) Manson-Haferd method:
d) Manson-Succop method:
$\mathrm{PMH}=\left(\right.$ LOG $\left.\mathrm{t}_{\mathrm{r}}-\mathrm{LOGt}^{*}\right) /\left(\mathrm{T}-\mathrm{T}^{*}\right)$
$P M S=L O G t_{r}-B . T$

where $t_{r}=$ rupture time ( in $h$ ), $T=$ temperature (in $K$ ), A, B, C, LOGtr ${ }^{*}$ and $\mathrm{T}^{\star}$ are constants in each method.

The methods of Larson-Miller and Manson-Haferd consider convergence, while the methods of Orr-Sherby-Dorn and Manson-Succop consider paralelism among the iso-stress lines, respectively in the spaces LOG $t_{r} \times 1 / T$ and LOG $t_{r} \times T$, as shown in the diagrams of Figure 1.

\footnotetext{
* Technical contribution to the $69^{\text {th }} A B M$ International Annual Congress and to the ENEMET, July $21^{\text {st }}-25^{\text {th }}, 2014$, São Paulo, SP, Brazil.
} 


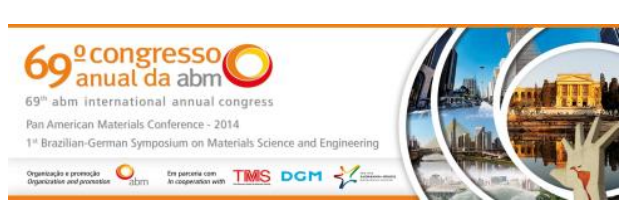

\section{MATERIAL AND METHODS}

In Part 1 of this work this session was presented in detail, but the main points are here described again.

The material was supplied in the form of plate with $220 \times 220 \times 25(\mathrm{~mm})$ that was hot rolled and subjected to thermal treatment of type T7351. Specimens both for the hot tensile and creep tests were extracted from the rolling direction of the material and had the same shape and dimensions, as shown in Figure 2, i.e. they were flat with gauge-length $L o=45 \mathrm{~mm}$, cross-section with width $x$ thickness of $8 \times 4 \mathrm{~mm}$.

The hot tensile tests were carried out with an universal testing machine made by TIME Groups, model WDW 100E, with 10000 kgf capacity. The tests were performed at constant cross-head speed, without the use of extensometry localized in the gauge-length of the specimens, i.e. they were carried out at nominal constant strain rate. Three temperature levels were used: 133,163 and $193^{\circ} \mathrm{C}$. At each temperature level, three cross-head speeds were employed: $20,0.5$ and $0.01 \mathrm{~mm} / \mathrm{min}$. Altogether, 9 different tensile test conditions were explored.

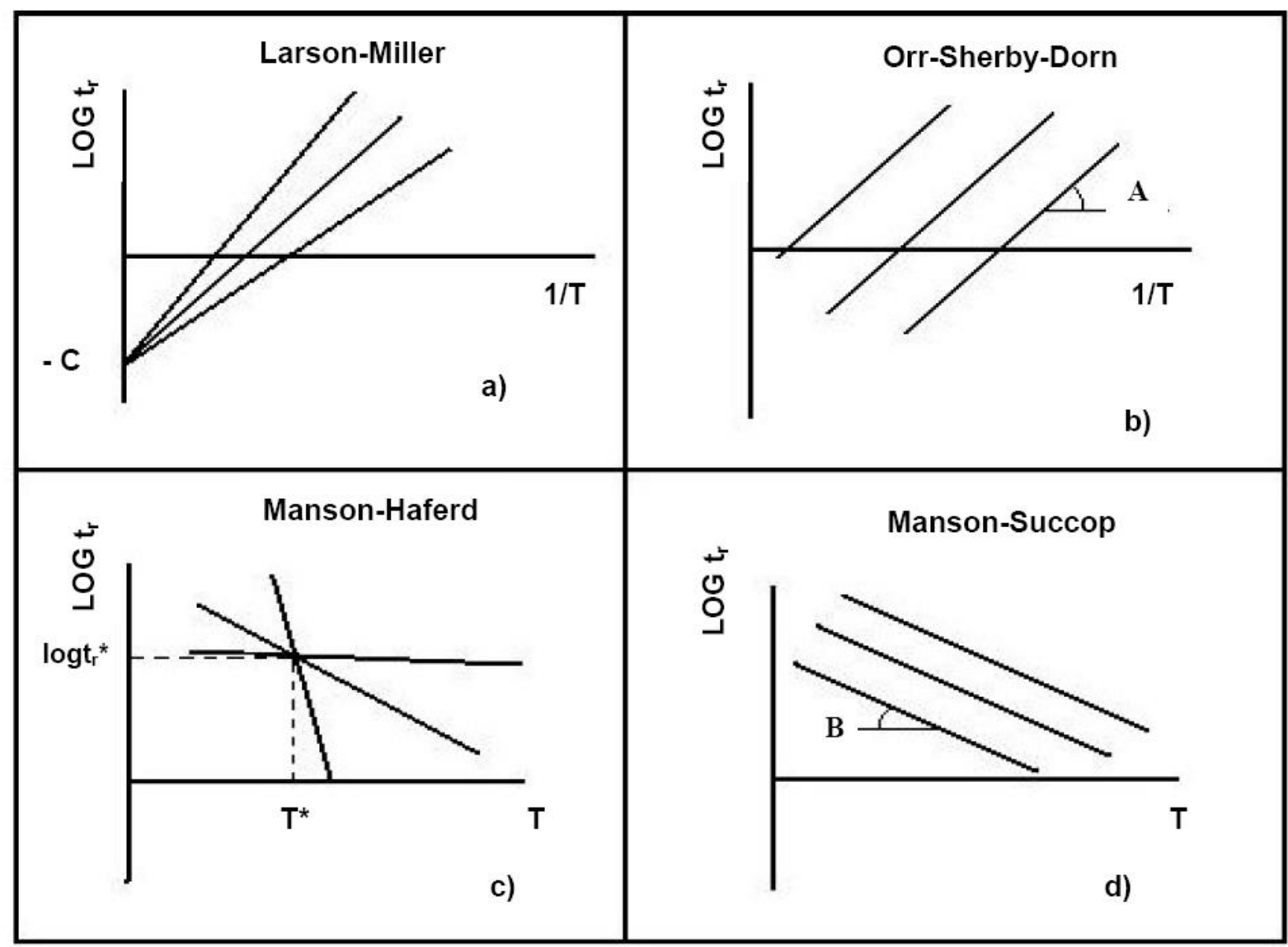

Figure 1. Schematic representation of the iso-stress lines pattern of the parameterization methodologies: a) Larson-Miller; b) Orr-Sherby-Dorn; c) Manson-Haferd; d) Manson-Succop.]

* Technical contribution to the $69^{\text {th }} A B M$ International Annual Congress and to the ENEMET, July $21^{\text {st }}-25^{\text {th }}$, 2014, São Paulo, SP, Brazil. 

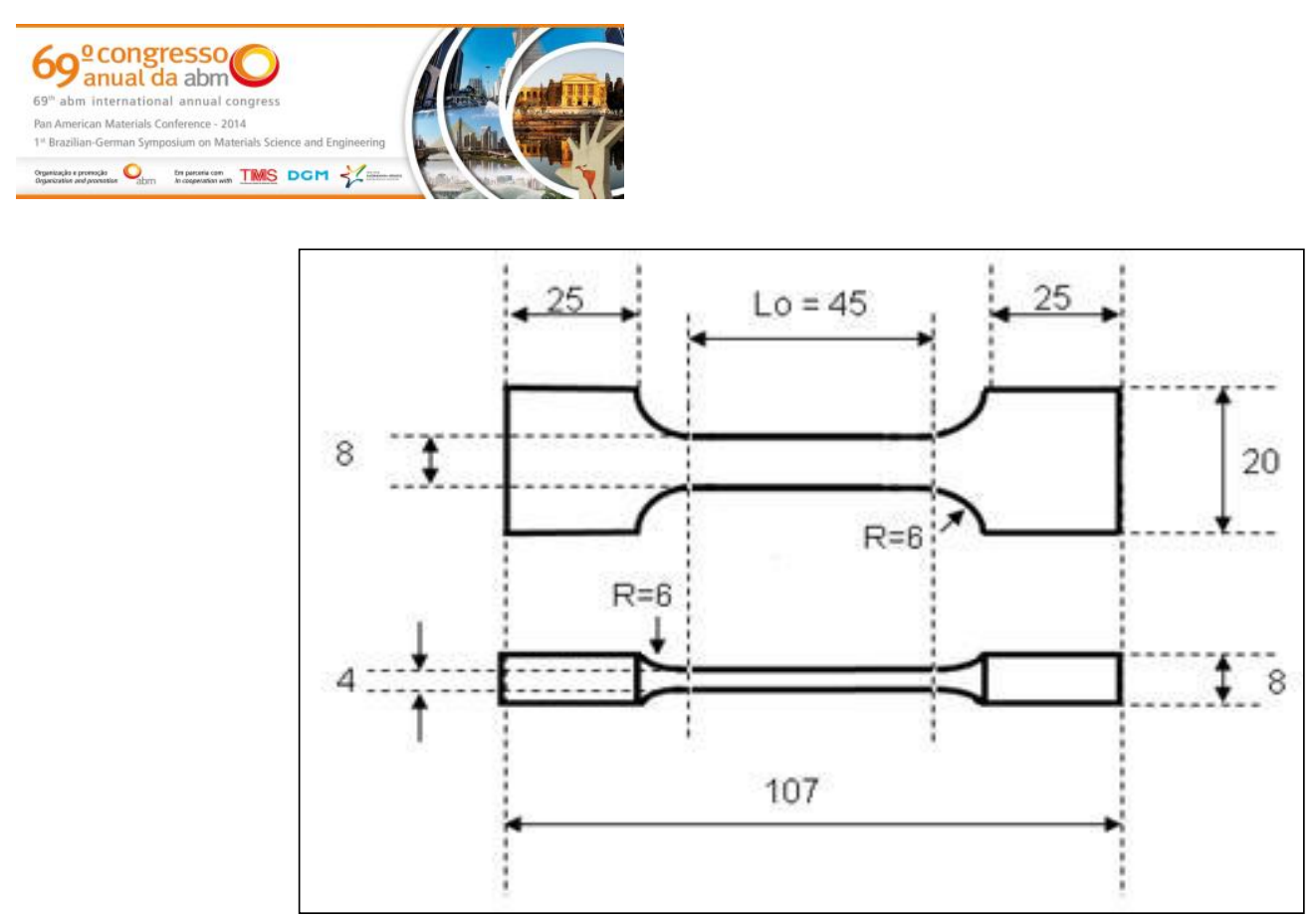

Figure 2. Schematic drawing illustrating the shape and dimensions of the hot tensile and creep specimens.

The creep tests were carried out in creep machines made by STM, model STMMF/1000, with $1000 \mathrm{kgf}$ capacity. The tests were performed at constant load, with the use of extensometers employing LVDTs, connected to the grips and not directly to gauge-lengths of the specimens. Also three temperature levels were used: 133, 163 and $193^{\circ} \mathrm{C}$ and different levels of nominal applied stress were employed, namely: 330,370 and $400 \mathrm{MPa}-$ at $133^{\circ} \mathrm{C}, 230,280$ and $310 \mathrm{MPa}-$ at $163^{\circ} \mathrm{C}, 140,190$ and $220 \mathrm{MPa}-$ at $193^{\circ} \mathrm{C}$. Also 9 different creep test conditions were explored with rupture times varying from about $4 \mathrm{~min}$ to $120 \mathrm{~h}$.

Hot Tensile and creep tests were carried out at homologous temperature of the order of $T_{h}=0.50$ to 0.57 .

To avoid confusion, and for more clarity, in the present article (and also in Part 2) the following nomenclature will be adopted for the variables involved in the two groups of test: a) the term Stress will be use in general, instead of Ultimate Tensile Stress in the hot tensile tests, and Stress applied in the creep tests; b) the term Strain Rate will be use in general, instead of Strain Rate applied in the hot tensile tests, and Minimum Creep Rate in the creep tests; c) the term Time will be use in general, instead of Time do reach the UTS in the hot tensile tests, and Rupture Time in the creep tests.

All values mentioned in this work for Stress, Strain and Strain Rate correspond to the nominal values and not the true values of these variables.

\section{RESULTS AND DISCUSSION}

Figure 3 presents the variation of LOG (Stress) with LOG (Time) including the whole set of hot tensile and creep data.

* Technical contribution to the 69th $A B M$ International Annual Congress and to the ENEMET, July $21^{\text {st }}-25^{\text {th }}, 2014$, São Paulo, SP, Brazil. 


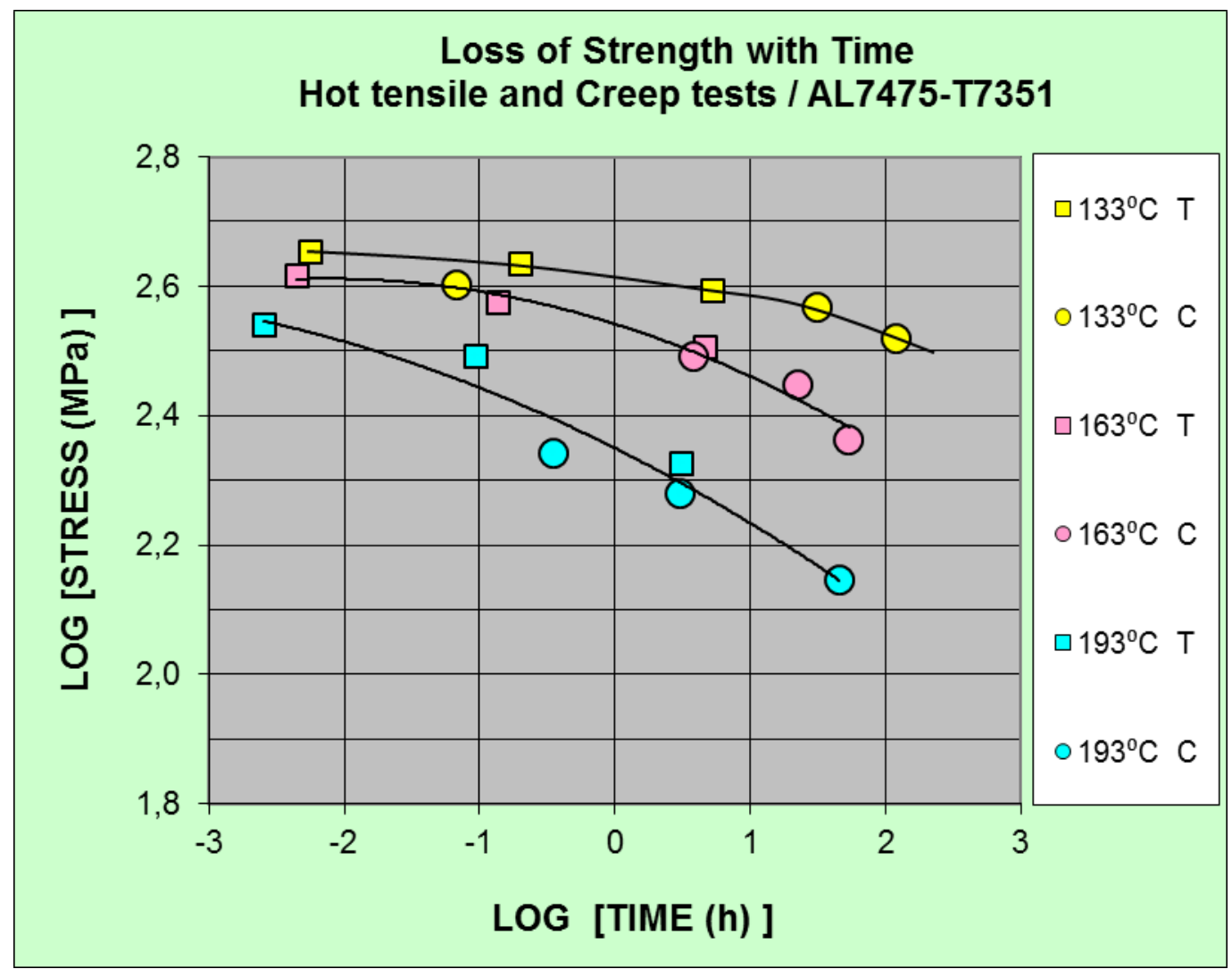

Figure 3. Loss of Strength with Time for alloy AL7475-T7351.

This graph is often referred to as the diagram of Loss of Creep Strength with Rupture Time in creep literature. Although the amount of data is limited in both cases, it can be noticed that the hot tensile results presents good compatibility with the creep results. In this figure (and the others subsequent) the letter T stands for Hot Tensile Test, and the letter $\mathrm{C}$ stands for Creep Test.

What the parameterization methodologies seek is the transformation of this kind of graph with different curves representing the isolated iso-temperature sets of data into a single curve that represents all the data collapsed into a unique set of data.

Due to the limited amount planned for creep tests, it was impossible to perform them in constant stress conditions, what would be essential for investigating the pattern of the iso-stress lines shown in Figure 1, so as to derive the constants of each parameterization methodology, according to Equations 1 to 4 . Using the curves fitted to the data in Figure 3, however, it was possible to make an estimation of the LOG(Time) values for the following stress levels: $398 \mathrm{MPa}(\mathrm{LOG}(\operatorname{tr}) \approx 2.6), 316 \mathrm{MPa}$ $(L O G(\operatorname{tr}) \approx 2.5)$ and $251 \mathrm{MPa}(\mathrm{LOG}(\operatorname{tr}) \approx 2.4)$. With this data, it was possible to organize the plots of LOG(Time) versus $1 / T$ and LOG(Time) versus $T$, to derive the constants of the four methods of data parameterization.

Figure 4 shows the graph of LOG(Time) versus 1/T with the three sets of iso-stress data mentioned above, and their respective straight line equations. Ideally, a minimum number of 5 iso-stress sets of this type would be necessary for a more consistent calculation of the various constants. With the present results, the average value of the Larson-Miller constant was estimated to be $\mathrm{C}=33$. For the Orr-SherbyDorn method the average constant was estimated to be $A=14656$.

Figure 5 shows the graph of LOG(Time) versus T, also with the same three sets of iso-stress data. Since only 3 iso-stress lines are present in this plot, the convergence of these lines into a focal point in the $1^{\text {st }}$ quadrant of the graph is improbable to be

* Technical contribution to the $69^{\text {th }} A B M$ International Annual Congress and to the ENEMET, July $21^{\text {st }}-25^{\text {th }}$, 2014, São Paulo, SP, Brazil. 
verified, to determine the constants $\mathrm{T}^{*}$ and LOGtr* corresponding to the method of Manson-Haferd. Therefore, in this case, it was imagined that the iso-stress lines make convergence in a point situated in the $\mathrm{Y}$-axis, i.e. it is assumed that $\mathrm{T}^{*}=0$ ( in a manner similar to the Larson-Miller method, where convergence is assumed to occur in the $Y$-axis in the space $L O G(\operatorname{tr})$ versus $1 / T$ ). Thus, the average values value of the Manson-Haferd constant LOGtr* is LOGtr* ${ }^{*}=34.097$. In the case of the Manson-Succop method, the average constant was estimated as $\mathrm{B}=-0.0777$.

Figure 6 presents the parameterization of the data shown in Figure 3 according to the method of Larson-Miller, using the constant $\mathrm{C}=33$. It is observed the two kinds of data (hot tensile and creep) collapse into a unique set of data, that can be well represented by the $3^{\text {rd }}$ degree polynomial indicated in the figure, with good correlation coefficient $\left(R^{2}=0.96932\right)$. The correspondence that the hot tensile data present with the creep data is remarkable in this diagram. It is interesting to comment that the value $\mathrm{C}=33$ is well above the value of $\mathrm{C}=20$ widely used for the Larson-Miller methodology for metallic materials in general [8]. In the analysis of hot tensile and creep data for commercially pure aluminium [5] the value of $C$ was determined as $\mathrm{C}=20.88$. The present material, being a high strength aluminium alloy with a complex pattern of precipitation, will certainly exhibit a higher $\mathrm{C}$ value, since the value of this constant is also connected to the creep activation energy of the material [8]. In Part 1 of this article it was shown that for AL7475-T7351 the value of $Q_{c}=333 \mathrm{~kJ} / \mathrm{mol}$, whilst for commercially pure aluminium the value of $Q_{c}$ was found to be $\mathrm{Q}_{\mathrm{c}}=212 \mathrm{~kJ} / \mathrm{mol}[1,5]$.

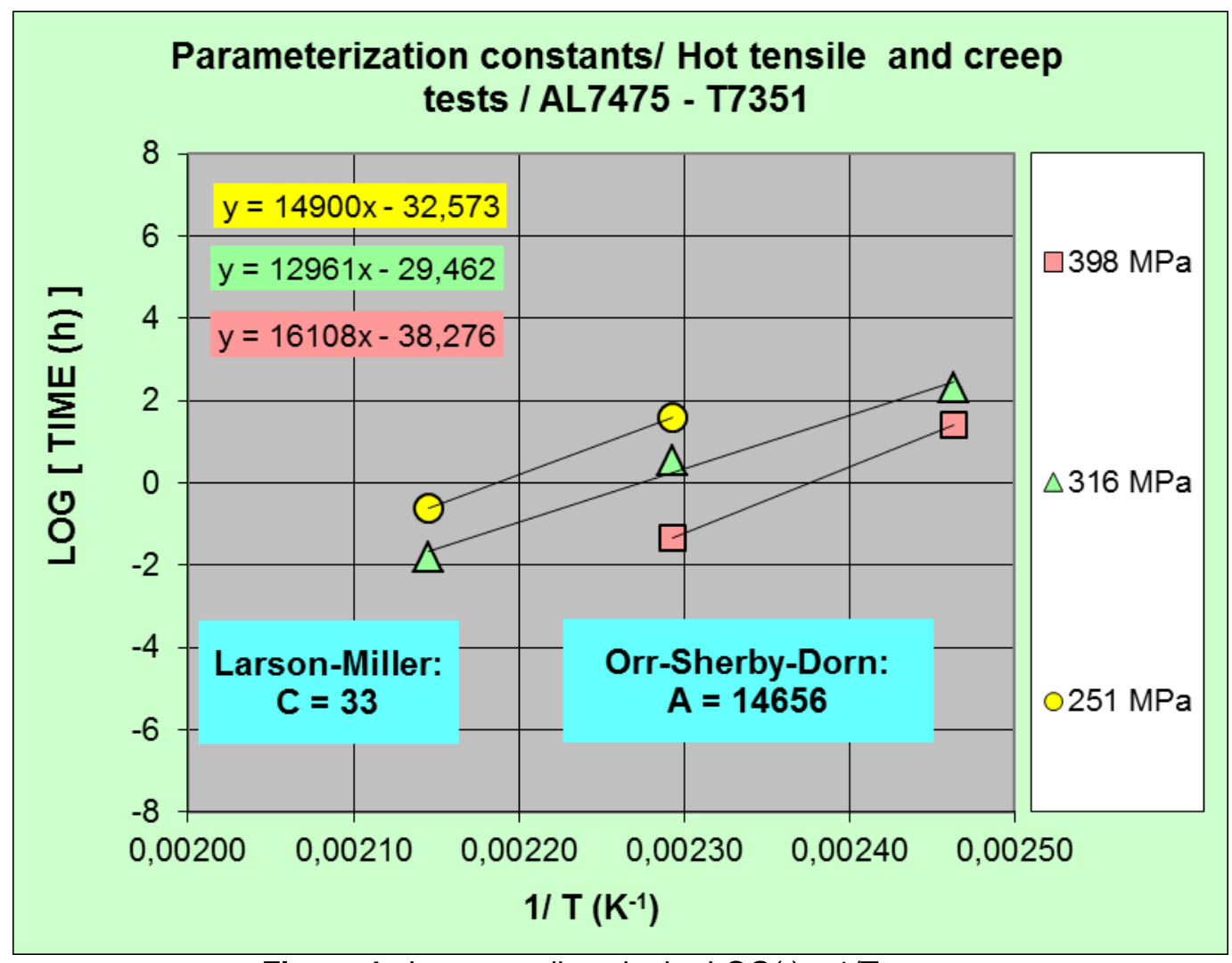

Figure 4. Iso-stress lines in the $\mathrm{LOG}(\mathrm{t}) \times 1 / \mathrm{T}$ space.

\footnotetext{
* Technical contribution to the $69^{\text {th }} A B M$ International Annual Congress and to the ENEMET, July $21^{\text {st }}-25^{\text {th }}$, 2014, São Paulo, SP, Brazil.
} 


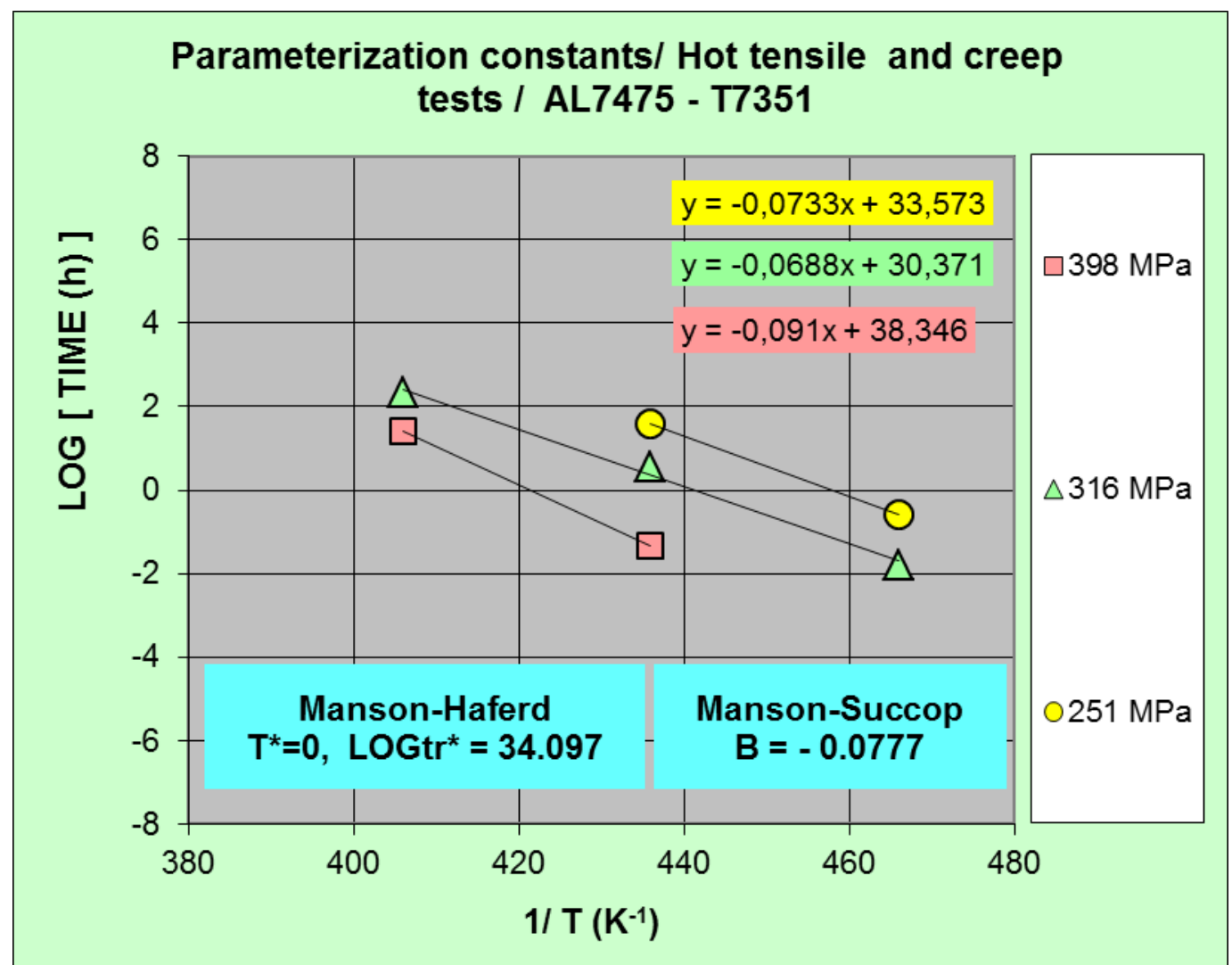

Figure 5. Iso-stress lines in the LOG(t) $\times$ T space.

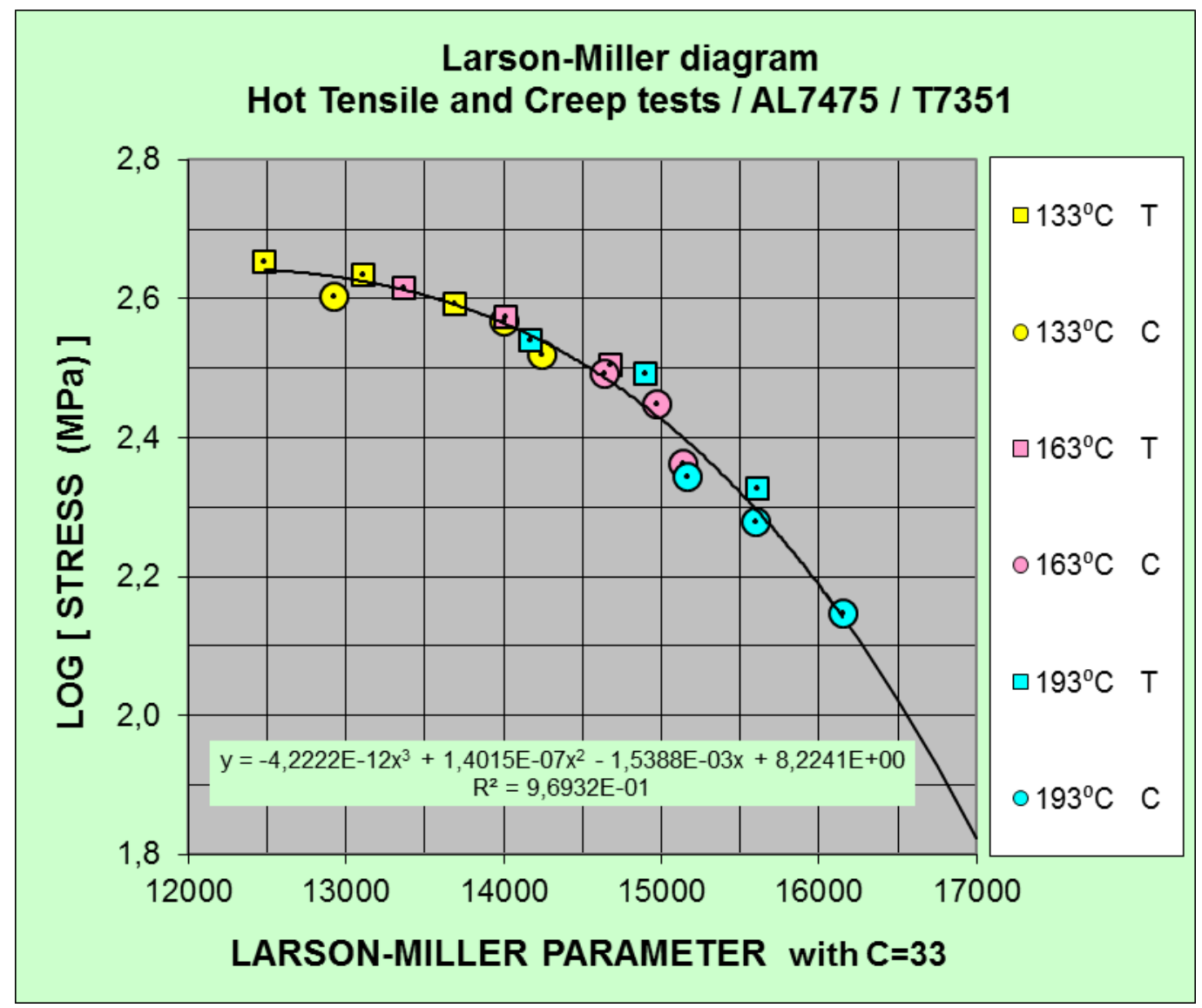

Figure 6. Hot Tensile and Creep data parameterized by the Larson-Miller methodology.

* Technical contribution to the $69^{\text {th }} A B M$ International Annual Congress and to the ENEMET, July $21^{\text {st }}$-25th, 2014 , São Paulo, SP, Brazil. 
Figure 7 shows the parameterization of the hot tensile and creep data according to the Orr-Sherby-Dorn method, using the constant $A=14656$. It is observed the two kinds of data (hot tensile and creep) collapse into a unique set of data, very similar the parameterization of Larson-Miller, that can be also well represented by the $3^{\text {rd }}$ degree polynomial indicated in the figure, with similar correlation coefficient $\left(R^{2}=0.96939\right)$.

In the same way, Figure 8 shows the parameterization of the data according to the Manson-Haferd method, using the pair of constants: $\mathrm{T}^{*}=0$ and LOGtr ${ }^{*}=34.097$, and Figure 9 the parameterization of the data according to the Manson-Succop method, using the value of the constant $B=-0.077$, in both cases with the $3^{\text {rd }}$. polynomial fit.

The Manson-Haferd method presented a slightly better quality of fit, judging from its value of $R_{2}=0.97024$. However, the difference in $R^{2}$ values among the four methods is very low, and the result of parameterization with these four methods can be considered equivalent to each other. Therefore, the method of Larson-Miller, which is more popular and widely employed, can be adopted for expressing the results.

Figure 10 presents a test of the predictive capability of the Larson-Miller method in expressing the data of Loss of Strength with time, shown in Figure 3. It can be observed that the iso-temperature lines calculated with this methodology agree quite well with the experimental data from the hot tensile and creep tests. Care should be taken, however, in the use of such procedure for extrapolation of data much beyond the range of the experimental data.

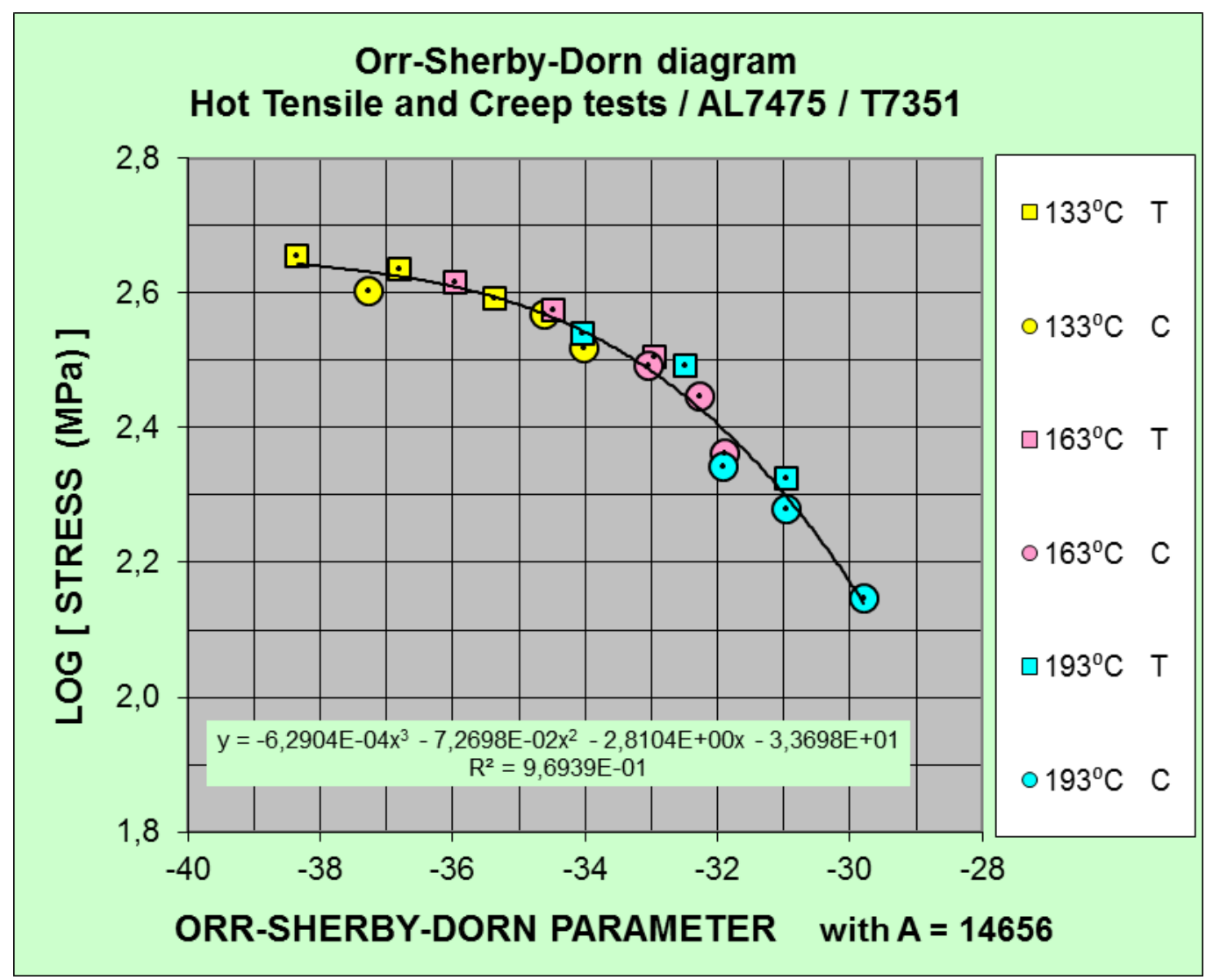

Figure 7. Hot Tensile and Creep data parameterized by the Orr-Sherby-Dorn methodology.

\footnotetext{
* Technical contribution to the $69^{\text {th }} A B M$ International Annual Congress and to the ENEMET, July $21^{\text {st }}-25^{\text {th }}$, 2014, São Paulo, SP, Brazil.
} 


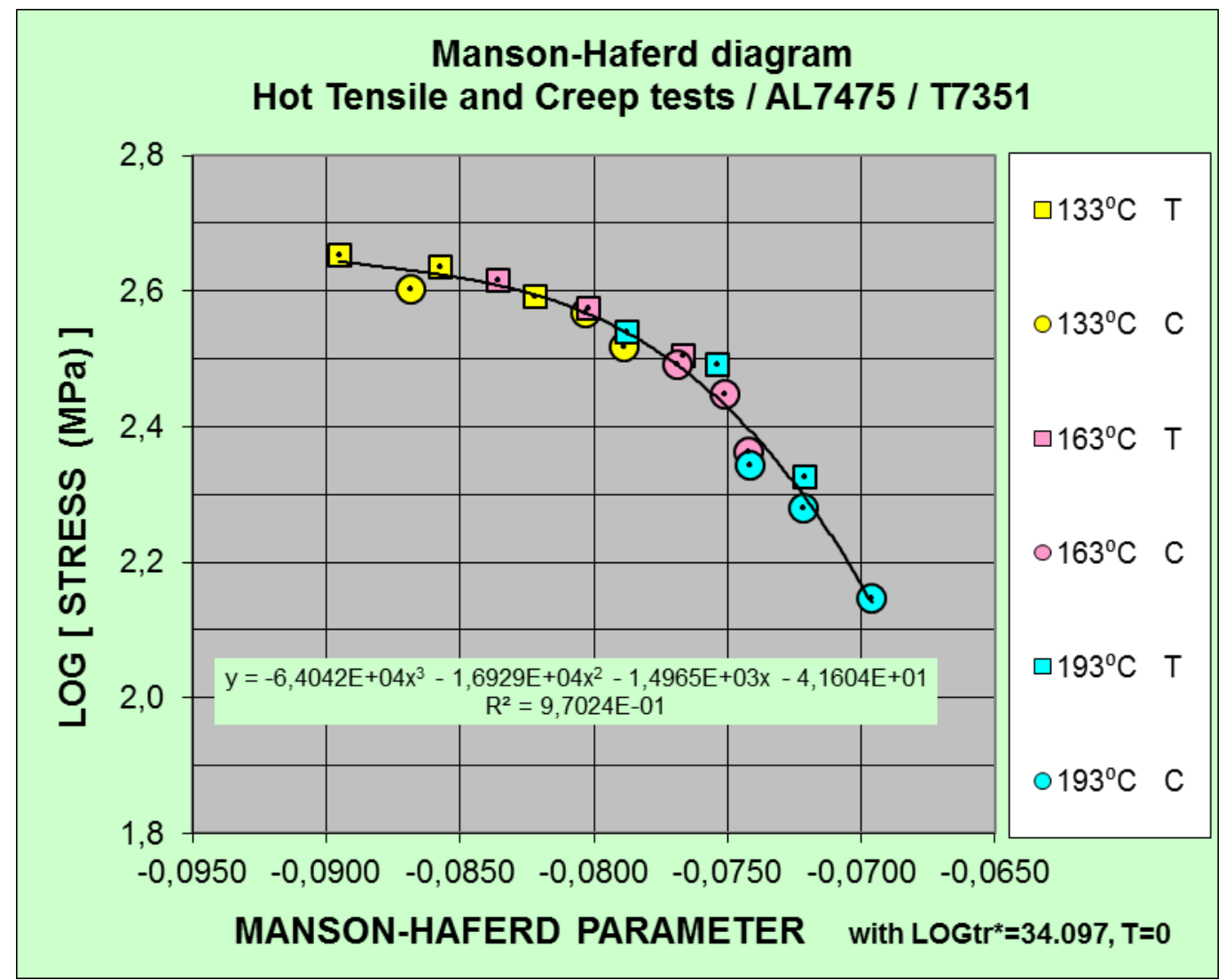

Figure 8. Hot Tensile and Creep data parameterized by the Manson-Haferd methodology.

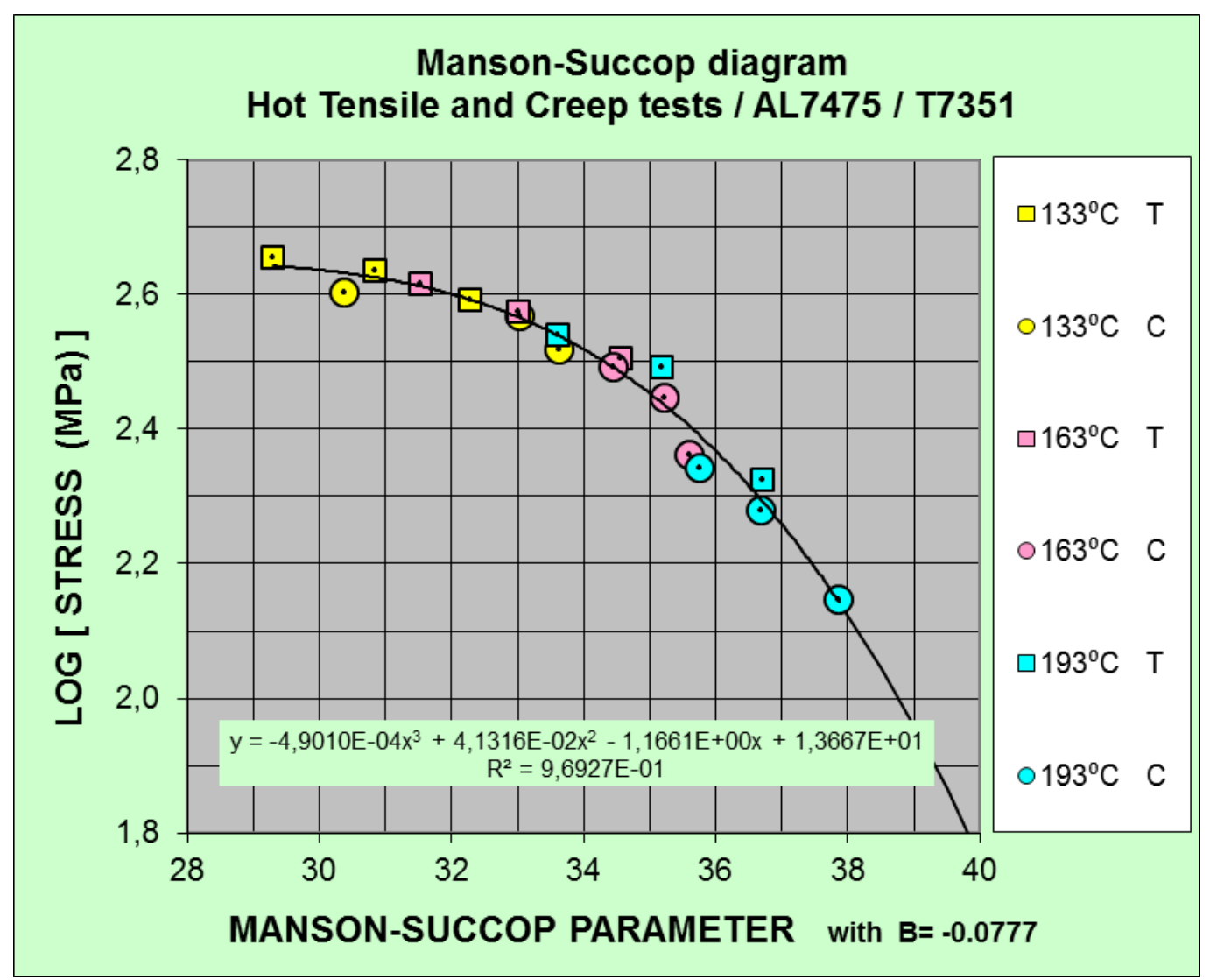

Figure 9. Hot Tensile and Creep data parameterized by the Manson-Succop methodology.

\footnotetext{
* Technical contribution to the $69^{\text {th }}$ ABM International Annual Congress and to the ENEMET, July $21^{\text {st }}-25^{\text {th }}, 2014$, São Paulo, SP, Brazil.
} 

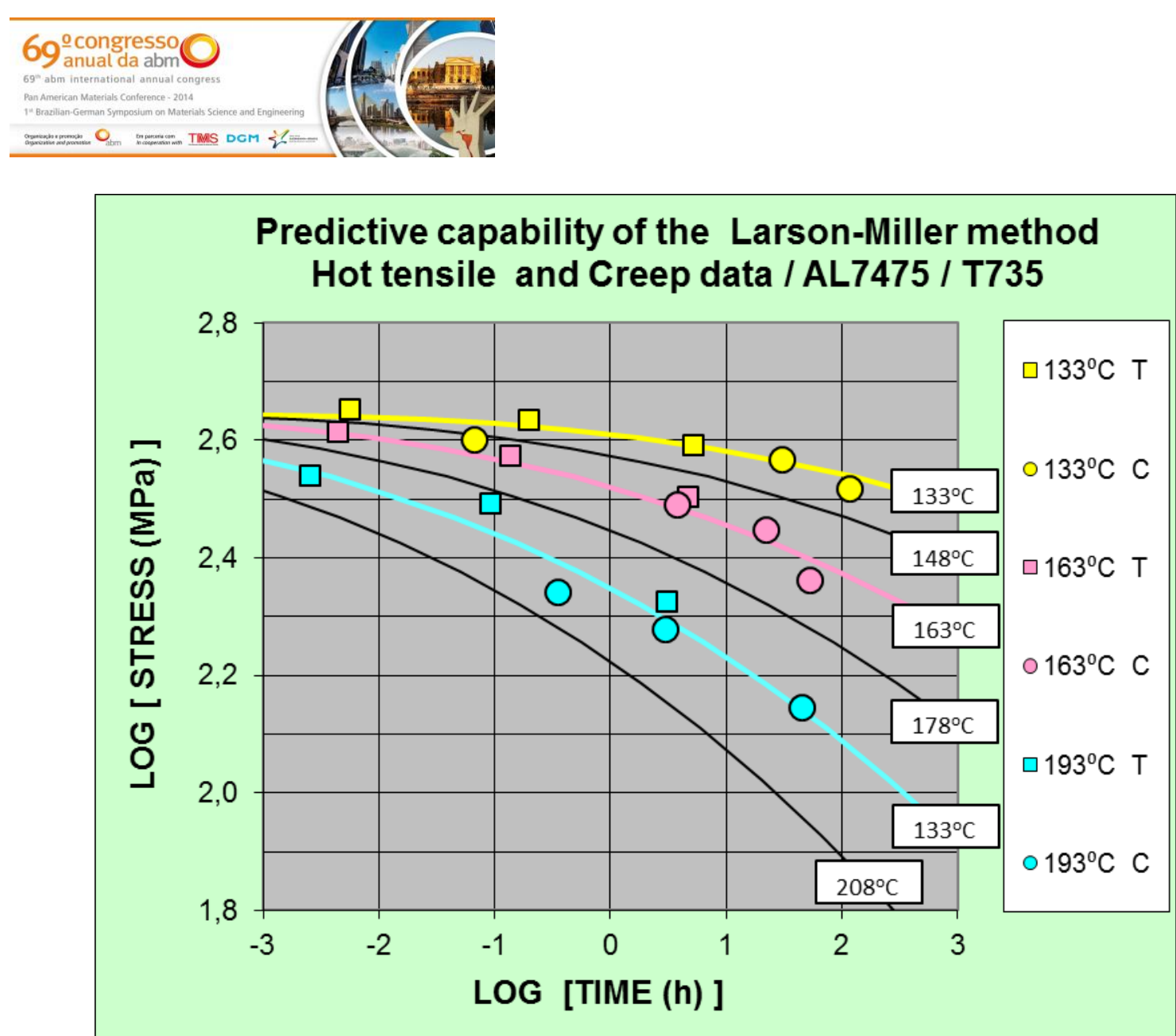

Figure 10. Predictive capability of the Larson-Miller parameterization in expressing the Loss of Strength with time.

Figure 11 presents the hot tensile data and creep plotted in the form of a Norton diagram: LOG(Strain Rate) versus LOG(Stress). This the kind of diagram is used when attempt is made to verify the validity of Norton relation: $\dot{\varepsilon}_{\min }=A$. $\sigma^{n}$, as commented in Part 1 of this article [1]. It was also shown in that work that the hot tensile and creep data can be well expressed by the Monkman-Grant equation: $\dot{\varepsilon} \times \mathrm{t}^{\mathrm{m}}=\mathrm{K}$, with $\mathrm{m}=1.2899$ and $\mathrm{K}=2.6080$.

If a combination is made between the Larson-Miller parameter and the MonkmanGrant equation it is possible to predict the Strain Rate data using the Larson-Miller methodology. The combined parameter would have the following formulation: PLM$M G=T\left(C+L O G(K / \dot{\varepsilon})^{1 / m}\right)$. For the analysis of the present results, PLM-MG $=T($ $\left.33+\operatorname{LOG}(2.6080 / \dot{\varepsilon})^{1 / 1.2899}\right)$.

The result of the analysis using the Larson-Miller/Monkman-Grant methodology can be observed in Figure 12. The iso-temperature sets of strain rate data from the hot tensile and creep tests shown in Figure 11 are collapsed also into a single set of data in Figure 12, that could be well adjusted also by $3^{\text {rd }}$. a polynomial, with very good regression coefficient, $R^{2}=0.98279$.

A test of the predictive capability of this methodology in expressing the experimental results is presented in Figure 13. It can be observed that the iso-temperature lines calculated with the LM-MG methodology agree quite well with the experimental data from the hot tensile and creep tests. The result is very similar to the result obtained with the methodology of Zener-Hollomon, shown in Part 1 of this work [1]. It is important to mention always that care should be taken in the use of such procedure for extrapolation of data much beyond the range of the experimental data.

Publications in literature about the correlation between hot tensile and creep results are very scarce. Remark should be done to the work of Steen [9], Osgerby and

\footnotetext{
* Technical contribution to the $69^{\text {th }} A B M$ International Annual Congress and to the ENEMET, July $21^{\text {st }}-25^{\text {th }}$, 2014, São Paulo, SP, Brazil.
} 
Dyson [10], Oh [11] and Goldenberg [12]. Steen [9] and Osgerby and Dyson [10] established correlation between stress and strain rate, in the same way done in the methodology of Bueno [2]. However, these authors did not establish a correspondence in the hot tensile test for the rupture time in test creep. The work of Osgerby and Dyson [10] is important by the fact that their approach is supported by a physical model using mechanisms-based equations for creep behavior, as exposed in Part 1 of this article [1]. With their model it becomes possible to predict the variation of stress as a function of strain under constant strain rate, based on the creep behavior theory of Dyson and McLean [13]. The use of the Osgerby and Dyson methodology seems to provide a sound theoretical basis for explaining why the criterion proposed [2] for equivalence between hot tensile and test data works so well.

The correlation proposed by Oh [11] for equivalence between hot tensile and creep results is very similar to that proposed by Bueno [2], as presented in Part 1 of this article[1]. This author, however, makes an oversimplification in his procedure of analysis, by taking the result of only one hot tensile test carried out at a certain temperature, combined with the Larson-Miller method with $\mathrm{C}=20$, to predict creep stain rates and rupture times.

The correlation proposed by Goldenberg [12] is based on phenomenological and statistical-thermodynamics equations assumed as valid for both phenomena. The author remarks, however, that the equations are based on the assumption of a single deformation mechanism controlling both short-time and long-time behavior, which is also an oversimplification of real creep happening in most of situations in engineering, as commented in Part 1 of this article [1].

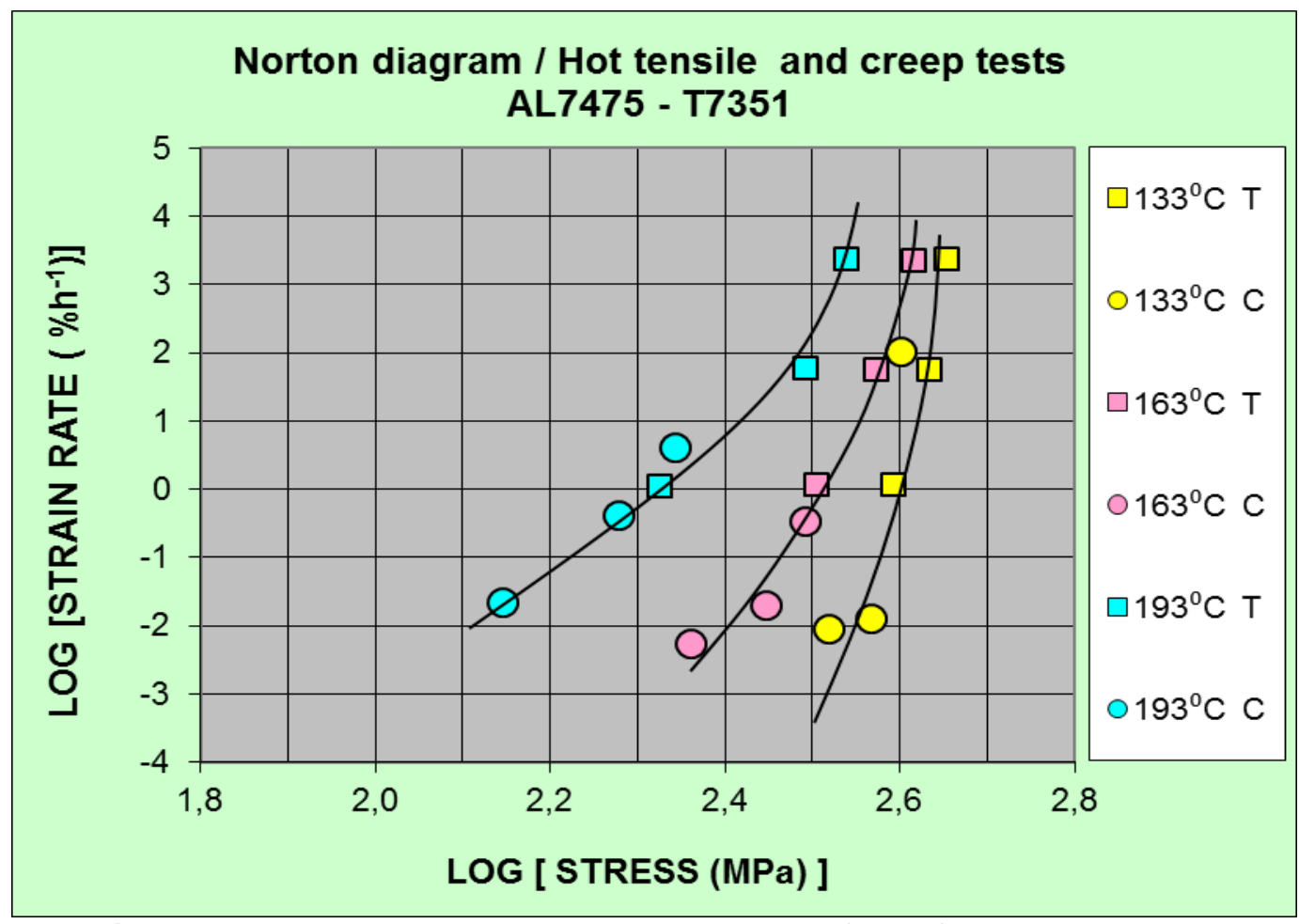

Figure 11. Hot tensile and creep data plotted in the form of a Norton diagram.

\footnotetext{
* Technical contribution to the 69th ABM International Annual Congress and to the ENEMET, July $21^{\text {st }}-25^{\text {th }}, 2014$, São Paulo, SP, Brazil.
} 


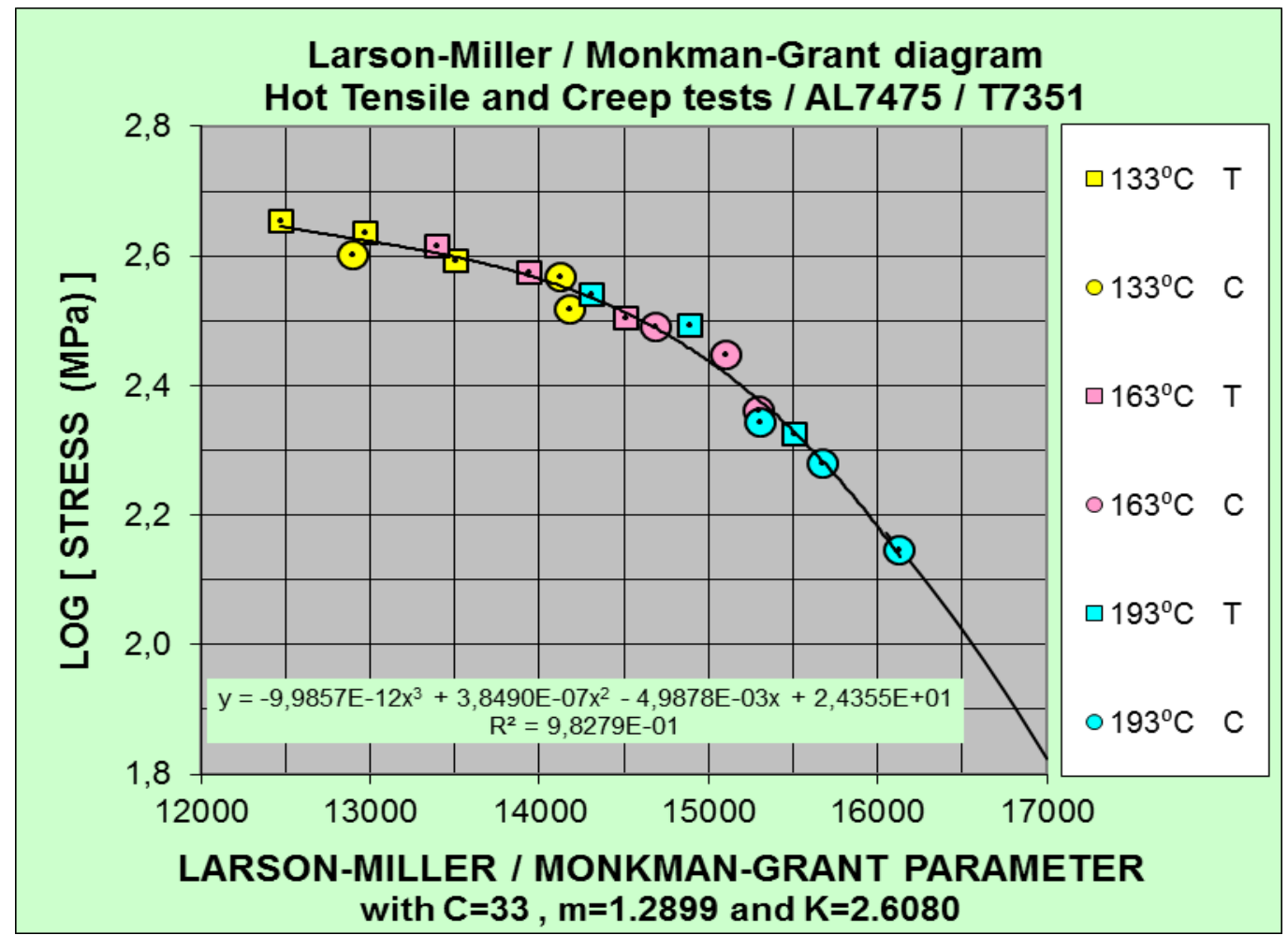

Figure 12. Hot tensile and creep data parameterized by the Larson-Miller/Monkman-Grant methodology.

According to this theory [12], as related by Chen et al [14], the iso-temperature data in a plot of the Loss of Strength with Rupture Time would appear as parallel straight lines, which is a situation very far from reality, as found for most of metallic materials in the last six decades of work in the area of creep in metals [7]. Figure 3 shows that this is not the case with AL7475-T7351.

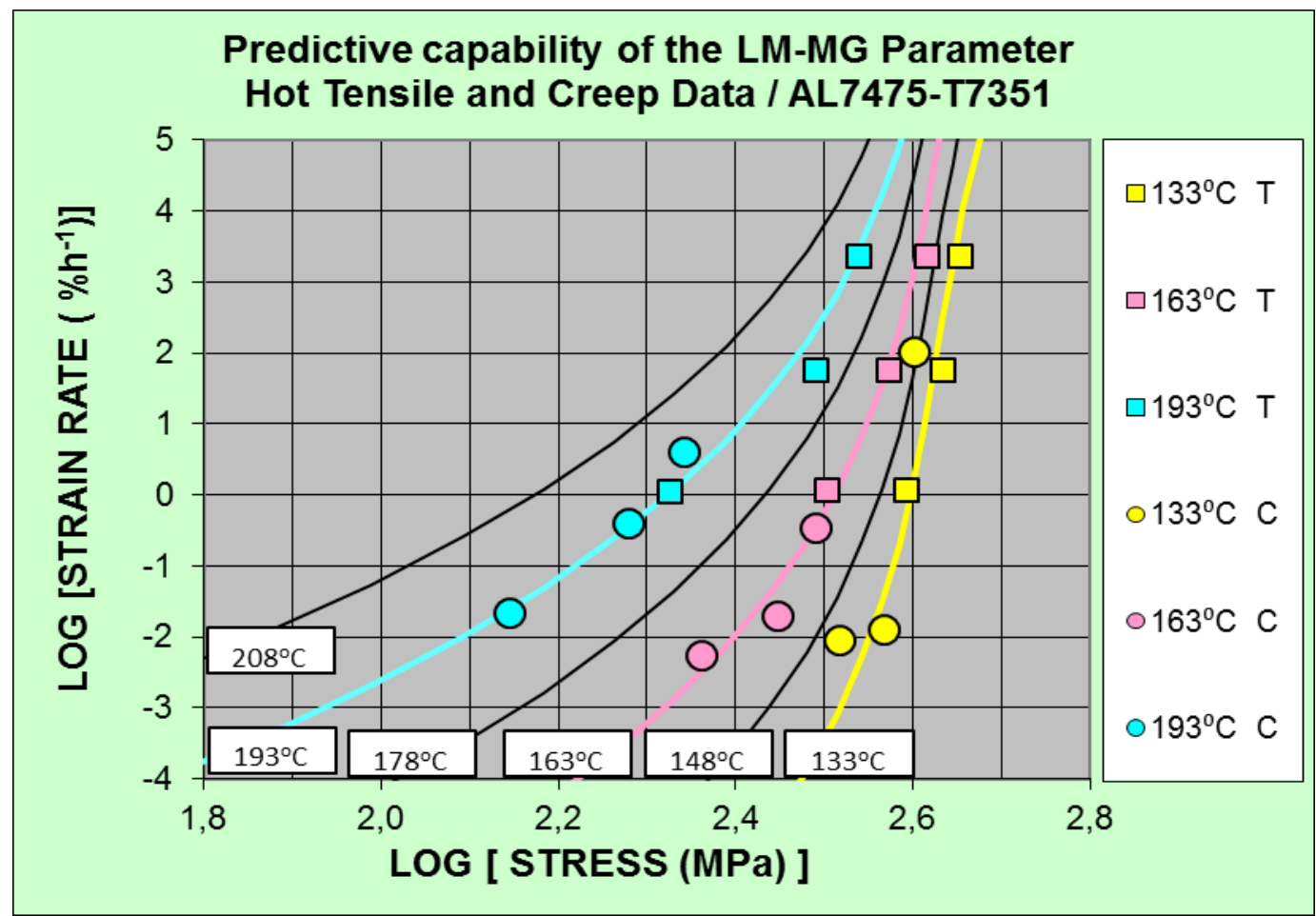

Figure 13. Predictive capability of the combined LM-MG parameterization in expressing the variation of strain rate with stress.

* Technical contribution to the $69^{\text {th }} A B M$ International Annual Congress and to the ENEMET, July $21^{\text {st }}-25^{\text {th }}$, 2014, São Paulo, SP, Brazil. 


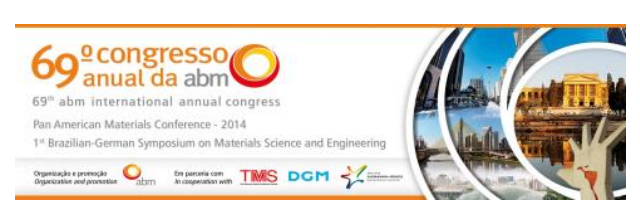

It seems also that, according to the Goldenberg analysis [12], the diagram for data extrapolation of Orr-Sherby-Dorn (and maybe others like Larson-Miller, MansonHaferd and Manson-Succop) would be always expressed by straight lines, which is clearly not the case, as shown in Figures 6, 7, 8 and 9, and most of the cases in literature [7].

It is important to remark that Bueno's methodology [2] of equivalence was not proposed for the prediction long-time creep data from short-time hot tensile results. In fact, according to the criterion of equivalence [1], hot tensile results are equivalent to short-time creep test results and nothing more. The prediction of long time data can only be performed with data that are adequately long as well. It would be really difficult to use a tensile machine to generate data with durations higher than $10^{2}$ hours, let alone of the order of $10^{3}$ or $10^{4}$ hours. Reliable long-time data will continue to be calculated by extrapolation from creep data. Hot tensile results are helpful in complementing the left-hand side of diagrams like those of Figures 6, 7, 8 and 9.

\section{CONCLUSION}

The results obtained for the correlation between hot tensile data and creep data for AL7475-T7351, according to the methodology of equivalence between them [2], were highly satisfactory. As verified previously for other metallic materials [2-6], the criterion proposed for equivalence between both kinds of results, worked well also for this high strength aluminium alloy.

In the various situations involving correlation among variables such as Strain Rate, Time, Stress and Temperature, the proposed methodology enabled the use of a unique procedure of analysis for the hot tensile data together with the creep data, according to the main relations of proposed by various authors in the past for creep data parameterization, like: Larson-Miller, Orr-Sherby-Dorn, Manson-Haferd and Manson-Succop.

\section{Acknowledgments}

The authors acknowledges EMBRAER for giving permission for publication of this article.

\section{REFERENCES}

1 Bueno LO. Equivalence between Hot Tensile and Creep data in Aluminium Alloy AL7475-T7351. Part 1: Relations involving Stress, Strain Rate and Temperatu-re. Proc. of the $69^{\text {th }}$ ABM International Annual Congress, July $21^{\text {st }}-25^{\text {th }}$ July, São Paulo(SP), Brazil.

2 Bueno LO. Creep Behaviour of 2.25Cr-1Mo Steel - An equivalence between Hot Tensile and Creep testing data. ECCC Creep Conference, 12-14 September 2005, London Proc. Creep \& Fracture in High Temperature Components - Design and Life Assessment Issues - Edited by: I.A.Shibli, S.R.Holdsworth, G.Merckling. DEStech Publ., USA. 2005; 969-980.

3 Reis Sobrinho JF, Bueno LO. Correlation between Creep and Hot Tensile behaviour for 2.25Cr-1 Mo Steel from $500^{\circ} \mathrm{C}$ to $700^{\circ} \mathrm{C}$. Part 2: An Assessment According to Different Parameterization Methodologies. Revista Matéria. 2005; 10-3: 463 - 471.

4 Bueno LO, Dias CRF. Correlação Tração a Quente e Fluência para o Cobre Comercial Puro. Parte 2: Análise por diferentes Metodologias de Parametrização. Proc. $65^{\text {th }}$ Annual Congress of ABM, July 2010, Rio de Janeiro(RJ), Brazil. 2010; CDROM: 1264 1274. Also in Tecnologia em Metalurgia Materiais e Mineração. 2011; 8: 80 - 85.

\footnotetext{
* Technical contribution to the $69^{\text {th }}$ ABM International Annual Congress and to the ENEMET, July $21^{\text {st }}-25^{\text {th }}$, 2014, São Paulo, SP, Brazil.
} 
